\title{
New approaches to measurement and management for high integrity health systems
}

Albert Mulley, 1 professor, Angela Coulter,2 senior research scientist, Miranda Wolpert,3 professor, Tessa Richards, 4 senior editor/patient partnership, Kamran Abbasi4 international editor

1Dartmouth Institute for Health Policy and Clinical Practice, Geisel School of Medicine at Dartmouth, NH 03756, US

2Nuffield Department of Population Health, University of Oxford

${ }^{3}$ Evidence Based Practice and Child Outcomes Research Consortium, UCL

${ }^{4}$ The BMJ

Correspondence to: A Mulley albert.g.mulley.jr@dartmouth.edu

Accepted 15 March 2017

We need better tools to achieve the next generation reforms essential for delivering care that matters most to patients, say Albert Mulley and colleagues

Healthcare economies across the globe are in crisis. High income countries-whether their healthcare economies are market driven like the US or tax funded like the UK-are struggling with relentless demand for more services that are increasingly costly to deliver. Low and middle income countries are struggling to provide better and more equitable access to potentially lifesaving interventions while wisely allocating scarce resources across all sectors that affect human and social development. In rich and poor countries alike, policy makers, citizens, and health professionals are drawn to technology but are not learning how to use it most effectively or from mistakes made when its limits go unrecognised or unheeded. ${ }^{1}$

Variation in regional rates of therapeutic and diagnostic interventions and hospital based care exists globally with no measurable benefit in populations receiving more services. ${ }^{2-5}$ At the same time effective primary healthcare and social services that can have a greater effect on health and wellbeing are being underused. ${ }^{467}$ The failure to deliver the right care at the right time in the right place contributes to the waste of as much as $40 \%$ of healthcare expenditures. ${ }^{48}$

Recognition of this waste, which is often associated with harm to patients, has spurred health policy reforms across the globe. One common objective is people centred care, which focuses on the needs and wants of individuals and engages them in management of their own care, including behaviours that promote and sustain health and wellbeing. A policy forum held earlier this year, which included health ministers and other representatives from members of the Organisation for Economic Cooperation and Development and seven other countries, advocated a shift from "a system centred on providers to one centred on people's 
individual needs and preferences." The same shift has been advocated in China and for other countries investing heavily in developing healthcare economies. ${ }^{9-11}$

Reform has been successful in some settings, but nowhere has the scale of reform been sufficient to allay concerns about personalised care or about system sustainability. A high integrity health system is one dedicated to providing services that people need and want-no less but no more - and that puts the interests of patients and the public above those of all other stakeholders. ${ }^{12}$ In this analysis, we discuss how next generation reforms towards a high integrity health system will need to move from the "what" to the "how" of change, to reflect a greater understanding of the sources of resistance, and to take new approaches to measurement and management to guide system performance and innovation.

\section{Challenging assumptions}

We identified three prevailing assumptions about current healthcare provision that impede system change (table 1$){ }^{12}$

Firstly, that providing more services delivers more health and wellbeing. We know that healthcare in high income countries contributes relatively little to the health of populations or to the health and wellbeing of individuals across their life course. Educational opportunity, personal and social factors, behaviours, and life chances have a far more consequential role. ${ }^{13}$ ${ }^{14}$ Health systems do not exist to promote professional services or the use of new technologies, drugs, and devices or to fuel unrealistic expectations on the part of patients and their clinicians. ${ }^{15}{ }^{16}$ Such promotion leads to overuse of high risk, high cost healthcare services and products, while basic needs that confer greater value go unmet and the integrity of the health system falters.

The second assumption is that clinical evidence alone is sufficient to determine best treatment and its delivery. A high integrity health system manifests respect for patients' preferences and goals. This is increasingly enshrined in the health policies of governments but needs to be more manifest in day-to-day practice. Clinicians must engage, accurately inform, and support patients to understand what is realistically possible to achieve and to identify the trade-offs they are willing to make and the interventions they prefer. ${ }^{417} 18$

This level of engagement is not easy to achieve, but without it decisions are routinely made in the face of avoidable ignorance on both sides of the healthcare dialogue. As a result, interventions are given to people who would not choose them and are withheld from those who would. Waste and harm can reach alarming levels when system incentives and practice patterns bias decisions towards more costly and risky interventions. Support for patient 
engagement in care management and decision making has been shown to reduce avoidable ignorance, waste, and harm but has not been adopted at scale in any country. ${ }^{4} 1718$

The third assumption is that healthcare can only be delivered effectively by health professionals. This is true for surgery and other technical services, but medicine is a knowledge intensive service industry, in which the smallest replicable unit of service comprises the health professional or multidisciplinary team, the patient together with family and carers, and the bidirectional exchange of intelligence and support that is essential to coproduce value. ${ }^{417-20}$

Medical interactions often occur at the most trying of times, when professionals are stressed by competing demands on their time, and patients are feeling vulnerable and afraid. Next generation reforms will entail new models of service delivery by teams who are aware of the limitations as well as the benefits of medical interventions. These teams respect the expertise, capacity, and ingenuity that patients and caregivers can bring to decision making and prioritise empathy for the patients' circumstances, including the support that they may have from family, friends, and the wider community. Team members will hold themselves and each other accountable for understanding patients' goals. They will share knowledge and support to build capabilities and personal agency for themselves and patients. Design principles for engagement of patients at the front lines are the foundation of a high integrity health system. ${ }^{17-20}$

\section{Design principles}

Policy makers and other system leaders must understand how design principles for next generation reforms should differ from those of previous efforts. Maxwell's six “dimensions of healthcare quality" were used to guide reform of the NHS in $1984 .{ }^{21}$ Similarly in 2001 the Institute of Medicine (now the National Academy of Medicine) issued six "aims for improvement" to cross the "quality chasm."22 But neither of these noted the critical bidirectional learning between health professionals and patients.

Learning from populations to deliver value to individuals is the central strategic intent of a high integrity health system. We learn from populations about the efficiency and effectiveness of interventions, and we learn at the front lines about what individuals value most when outcome trade-offs are necessary.

Table 2 compares and contrasts design principles for high integrity health systems with Maxwell's quality dimensions and the Institute of Medicine's improvement aims. In a high integrity health system people engaged in coproduction of health are the essential source of 
learning what is valued. Successful implementation will require new measures and approaches to management that foster mutual accountability, from the front lines to system leadership, for decision making informed by what matters most to patients.

Reform efforts in the US (box 1) and UK (box 2) provide context for considering what these new measures and related management tools might look like.

\section{Box 1: The Affordable Care Act and new care models in the US} In 2010, the US Congress passed the Patient Protection and Affordable Care Act (ACA) to tackle concerns about cost and quality while expanding access to public and private health insurance to the tens of millions of American people who were uninsured. The legislation enabled new care models at the organisational level-accountable care organisations (ACOs) - and new care models to strengthen primary care-patient centred medical homes (PCMH). ACOs would be accountable for the quality and cost of care provided to patients. PCMHs would provide better access to care with more continuity, coordination, and patient engagement. Financial incentives would drive implementation of ACOs with fee-for-service shifting to global payments and eventually full capitation. Shared savings models would align interests of payers and providers; quality would be monitored with agreed measures. ${ }^{23}$ The ACA increased the number of American people with insurance by 20 million, and evidence indicates that ACOs have improved quality and satisfaction and achieved cost savings in some settings. ${ }^{24}$ Evidence indicates that PCMHs improve patient and staff experiences but have not yet demonstrated an effect on clinical and economic outcomes. ${ }^{25}$ With the change in government in 2017, the future of ACOs, PCMHs, and the ACA itself, are uncertain. ${ }^{26}$

Ambitious redesign of team based frontline care models showed more promise than PCMHs. For example, AtlantiCare and the Camden Coalition came to national attention in 2011. ${ }^{27}$ Both focused on people who are most vulnerable to having their needs not met in today's health system: in Atlantic City, people with multiple long term conditions; in Camden, people whose healthcare needs were driven by social and behavioural determinants. The models relied on recruitment and training of clinical team members with the skills and competencies necessary for patient engagement ${ }^{28} 29$

Investment in coaching and support roles for team based engagement of patients reduced demand for clinician time and improved staff and patient experiences. ${ }^{28}{ }^{29}$ Empathy and listening skills are prioritised over healthcare experience. Appropriate training and decision support assure high levels of competence in shared decision making, personal care planning, and motivational interviewing, which have been shown to improve the quality of clinical decisions, health outcomes, and health behaviours, respectively. Deep knowledge of community resources that can complement capabilities of patients and families is also essential for co-production. This care model borrows heavily from success in low resource settings where community health workers are elected or otherwise chosen for their commitment to building on the social capital that exists in the community. ${ }^{30}$

\section{Box 2: The Health and Social Care Act and new care models in the UK}

The UK's Health and Social Care Act (HSCA) was passed in 2012. As a result the NHS was restructured and its relations to new and old statutory bodies and to the Department of Health were reorganised. In late 2014, as these structural changes were still being implemented, the strategic direction of reform was set with publication of the Five Year Forward View. ${ }^{31}$ It aimed for a "triple integration" of primary care with acute care, physical health with mental health, and healthcare with social care. ${ }^{31}$ Its priorities were engagement and empowerment of 
patients in primary and secondary prevention, shared decision making, and personal care planning. A year earlier the "house of care" model was developed with engagement of patients in these processes as its starting point. ${ }^{19}$ The house of care model also argued that planning with patients for co-managing long term conditions was a form of "microcommissioning," if data documenting patients' goals and preferences could be captured, aggregated, and used to inform commissioning of services for populations.

The forward view defined new care models at the organisational level including Multispecialty Community Providers (MCPs) and integrated Primary and Acute Care Systems (PACSs). MCPs and PACSs would be responsible for closing health, quality, and finance gaps by achieving the triple integration and improving patient and community engagement. Like prospective ACOs in the US, MCPs and PACSs would develop capabilities to assume accountability for healthcare cost and quality for defined populations and, in effect, for achieving a fourth integration of purchasing and provision of services not envisioned in the HSCA. MCPs would begin in the community, comprised of expanded primary care group practices. PACSs would vertically integrate hospital services with GP, mental health and community care services. ${ }^{31}$

The forward view has had some early successes, including new care models with greater emphasis on integration of health and social care. But the NHS in England was facing considerable budgetary and performance pressures when the reform strategy was published, and those pressures have since increased. As in other countries, the transformation needed may seem beyond reach as fiscal crises and publicised performance failures undercut morale and lower the aspirations of providers, even as expectations of service users rise. In such a climate, new approaches to measurement and management can be the way forward with integrity of purpose in putting patients at the centre.

\section{Measuring what matters}

When motivated by concerns about cost and quality, assessment of system performance often relies on measures of clinical service provision, such as emergency attendance rates, hospital admissions, and lengths of stay. But because of failures to integrate service delivery across settings and people in interdependent roles, these measures offer little guidance to those responsible for performance improvement and even less to those responsible for innovation and system transformation. ${ }^{32} 33$

Measures commonly used to assess individual clinicians include the documentation of processes used in the care of patients with chronic conditions, such as diabetes and cardiovascular or respiratory diseases. When linked to financial incentives, such measures have been shown to increase reported rates of clinical activity in the population but are thought to have marginal impact on health outcomes that matter to patients. ${ }^{33}$

Measurement and transparent reporting can reveal variation in processes that underlie variation in outcomes and costs. Engaging and supporting patients to understand their needs and wants can increase value. But platforms designed to learn from variation, such as the Dartmouth Atlas in the US and the NHS Atlas in England, and decision aids designed to learn from individual patients and the choices they make have not been widely adopted by those 
who provide and pay for clinical services. ${ }^{2}{ }^{3}$ Even the developers of patient reported outcome measures rarely consult patients to learn which outcomes matter to them. ${ }^{10}$ No health system has succeeded in learning what patients need and want at scale.

New measures are needed to achieve the learning necessary to deliver value. Simple measures embedded in frontline practice can offer realtime feedback to service staff and users and support accountability for sharing in decisions, care planning, and coproduction and coordination of care. Did patients feel that they were helped to understand their health problems? Were they supported to express their goals and explain what mattered most to them? Did clinicians feel that patients actively participated in designing a care plan that reflected those goals? Was the quality of decisions and care plans for groups of patients reviewed to assure that they were informed and that management was concordant with goals and preferences ? $^{34-38}$ Under these circumstances, care choices made by individuals can guide commissioning and capacity planning as envisioned in the UK "house of care" model.

Implementating true innovation is an experiment. New types of measures or better use of existing ones could serve as leading indicators of success or failure. ${ }^{29}{ }^{35-38}$ Measures and tools for teamwork and coordination of care, for balancing population health metrics to include what matters to patients, clinicians, and payers, for managing improvement and innovation, for aligning capabilities against priority activities, and for testing assumptions to assure expectations about the amount and timing of returns on investments in population health are gaining use in health systems. ${ }^{29}{ }^{35-39}$ Such tools have the potential to foster deeper, more informed partnerships with patients, communities, and the professional service providers in other sectors (including education, employment, as well as social care) who contribute to health and wellbeing. Introduction of this approach to advance the reform goals of NHS England is described in box 3.

\section{Box 3: From what to how-implementing new care models in NHS England} In 2016, six teams representing MCPs and PACSs came together as a Place Based Care Network (PBCN). ${ }^{31}$ The goal was to accelerate learning about how to implement new care models as building blocks for accountable care systems across England. Over six months, supported by the NHS England New Care Models Team and the Dartmouth Institute for Health Policy and Clinical Practice, the six teams performed several tasks:

Using logic models they set priorities for learning how to better meet the needs and wants of priority populations, such as frail elderly people and children and adolescents with behavioural problems ${ }^{40}$

They used Right Care's Commissioning for Value Packs derived from the NHS Atlas of Health Care to identify opportunities for improving outcomes and costs by making process variation visible ${ }^{3}$ and to improve value by using shared decision making and care planning as a form of "micro-commissioning" to inform purchasing decisions made for populations $^{19}$ 
They considered embedding simple patient reported measures to gauge effort made by clinicians to learn what matters most to them after helping them understand their health problems ${ }^{34}$ and care coordination to guide implementation of multidisciplinary teams and new care models designed for learning ${ }^{35}$

They constructed "value compasses" to meet the needs of those accountable for quality and cost of care for populations while maintaining focus on what matters to patients 333641

They considered the role of microsystems and related improvement science measures and tools to strengthen teamwork and improve safety and productivity ${ }^{41}$

They explored the different management approaches needed for "performance improvement" and "innovation implementation" and the implications of trying to do both simultaneously ${ }^{29}$

Using a readiness assessment tool, they aligned priorities and capabilities for accountability within organisations and among organisations partnering to form accountable care systems

Using a systems dynamic model, they tested assumptions about health and wellbeing and financial returns on investments in acute care and community settings across health and social care ca $^{39}$

The PBCN pilot programme demonstrated that frontline clinicians and managers and purchasers of services were accepting of an integrated offering of measures and management tools to guide implementation of new care models. We need further evidence of acceptability in different contexts and of the effect of the integrated offering and its individual elements, even as such support programmes are refined and expanded in scope and scale.

\section{A way forward for The BMJ's initiative}

To spur debate on how to foster high integrity health care, The BMJ is seeking to publish a series of articles that will draw attention to new collaborative approaches to improving health and wellbeing of populations in different contexts and cultures at a sustainable cost to nations' economies. In the editorial that launched the high integrity health system initiative, we identified three populations that are particularly vulnerable and often marginalised: children and adolescents, especially those with mental and behavioural health problems; people of working age, especially those requiring support to get into or continue working; and people who need compassion and care because they are frail or dying. The series will start with three papers that review evidence for new coproduced services with and for these three populations; the first covering mental health services for children and young people. ${ }^{42}$

We invite readers across the globe who have examples or case studies of innovative services aimed at improving health across the whole life course to submit papers or discuss outline ideas for papers with us. These should describe the initiatives and, wherever possible, set out new measures and methods needed to test hypotheses about their effectiveness. They should also discuss how to overcome political, professional, and managerial obstacles to their implementation. Our aim is to foster a global community, across sectors, which is committed to advancing health through exploring and learning from new ways of working. 


\section{Key messages}

Overuse of high cost acute care and underuse of effective primary care contribute to waste that is unsustainable

New approaches to measurement and management are needed to implement next generation reforms that see people and patients as the essential source of learning in a high-integrity health system

Measurement should support the strategic intent of a HIHS to learn from variation at the population level to co-produce value that reflects individuals' goals and preferences

Management should support all stakeholders to hold themselves mutually accountable for decision making informed by the needs and wants of individuals and populations

The authors acknowledge the contributions of the six teams supported by the NHS England New Care Models Programme representing MCPs and PACSs from Barnsley, North East Hampshire, and Farnham, Salford, Southern Hampshire, West Birmingham and West Wakefield, and from Sustainability and Transformation Plan (STP) teams as they became active in their regions. We learned a great deal from the participants in the PBCN pilot about the practical application of the framework in moving from the 'what' to the 'how' of new care model implementation.

Contributors and sources: AM has studied and reported widely on learning from warranted and unwarranted variation in healthcare to deliver value to populations and individual patients. AC has studied and reported widely on the evidence for effects of shared decision making, personal care planning, PREMs and PROMs, and other forms of patient engagement. MW has studied and reported widely on evidence for children and younr people's mental health services (CYPMH), has advised local and national CYPMH policy, and leads development of THRIVE, a new care model for CYPMH and on measurement strategies for CYPMH. TR has studied and reported widely on patient engagement while leading The BMJ's initiatives in patient partnership. KA has studied and reported widely on international health care while serving as the BMJ's international editor. AM was responsible for writing the initial and final drafts based on working group discussions. AC, MW, TR, and KA contributed to further content and revisions. AM serves as guarantor. This article arose from the BMJ-Dartmouth on working group on high integrity health systems that has included Kamran Abbasi, Jo Bibby, Agnes Binagwaho, Angela Coulter, KK Cheng, Elliott Fisher, Fiona Godlee, John Lotherington, Albert Mulley, Srinath Reddy, Tessa Richards, and Miranda Wolpert.

Competing interests: We have read and understood BMJ policy on declaration of interests and declare the following: AM was Dartmouth lead on the Place Based Care Network pilot delivered with support of the NHS New Care Models Programme. AC has contributed to academic studies of PREMs and PROMS. MW studies the evidence base for CAMHS and advises on policy and service frameworks for CYPMH including the THRIVE model and outcomes frameworks developed by the Child Outcomes Research Consortium.

Provenance and peer review: Commissioned; externally peer reviewed.

$<$ jrn>1 Mulley AG Jr. The global role of health care delivery science: learning from variation to build health systems that avoid waste and harm. J Gen Intern Med 2013;28(Suppl 3):S64653.. PubMed doi:10.1007/s11606-013-2457-6</jrn>

$<$ eref $>2 \quad$ Dartmouth Atlas of Health Care. 1996-2017 www.dartmouthatlas.org/</eref> $<$ eref $>3$ Public Health England. The NHS atlases of variation in health and healthcare. 2010-2017. http://fingertips.phe.org.uk/profile/atlas-of-variation.</eref> $<$ jrn>4 Mulley AG. Inconvenient truths about supplier induced demand and unwarranted variation in medical practice. BMJ 2009;339:b4073. PubMed doi:10.1136/bmj.b4073</jrn> 
<jrn>5 Fisher ES, Wennberg DE, Stukel TA, Gottlieb DJ, Lucas FL, Pinder EL. The implications of regional variations in Medicare spending. Part 1: the content, quality, and accessibility of care. Ann Intern Med 2003;138:273-87. PubMed doi:10.7326/0003-4819138-4-200302180-00006</jrn>

$<$ jrn>6 Brownlee $\mathrm{S}$, Chalkidou K, Doust J, et al. Evidence for overuse of medical services around the world. Lancet 2017;S0140-6736(16)32585-5. doi:10.1016/S0140-6736(16)325855. PubMed $</$ jrn $>$

<jrn>7 Saini V, Garcia-Armesto S, Klemperer D, et al. Drivers of poor medical care. Lancet 2017;S0140-6736(16)30947-3. doi:10.1016/S0140-6736(16)30947-3. PubMed</jrn> <eref>8 WHO. The world health report. Health systems financing: the path to universal coverage. 2010. www.who.int/whr/2010/en/.</eref>

<eref >9 Hunt J, Taucher CC, Grohe H, et al. The next generation of health reforms. OECD Health Ministerial Meeting. 17 January 2017.

http://www.oecd.org/health/ministerial/ministerial-statement-2017.pdf</eref $>$

$<$ jrn>10 Coulter A. Measuring what matters to patients. BMJ 2017;356:j816. PubMed doi:10.1136/bmj.j816</jrn>

<eref>11 China Joint Study Partnership: World Bank Group, World Health Organization, Ministry of Finance, National Health and Family Planning Commission, Ministry of Human Resources and Social Security. Deepening health reform in China. Building high-quality and value-based service delivery. 2016.

https://openknowledge.worldbank.org/bitstream/handle/10986/24720/HealthReformInChina. pdf $</$ eref $>$

$<$ jrn $>12 \quad$ Mulley A, Richards T, Abbasi K. Delivering health with integrity of purpose. BMJ 2015;351:h4448. PubMed doi:10.1136/bmj.h4448</jrn>

$<$ bok $>13 \quad$ Marmot M. The health gap. The challenge of an unequal world. Bloomsbury, 2015. </bok>

$<$ jrn $>14 \quad$ McGinnis JM, Williams-Russo P, Knickman JR. The case for more active policy attention to health promotion. Health Aff (Millwood) 2002;21:78-93. PubMed doi:10.1377/hlthaff.21.2.78</jrn>

$<$ jrn $>15 \quad$ Hoffmann TC, Del Mar C. Patients' expectations of the benefits and harms of treatments, screening, and tests: a systematic review. JAMA Intern Med 2015;175:274-86.

PubMed doi:10.1001/jamainternmed.2014.6016</jrn>

$<$ jrn $>16 \quad$ Hoffmann TC, Del Mar C. Clinicians' expectations of the benefits and harms of treatment, screening and tests: a systematic review. JAMA Intern Med 2017;177:407-19. PubMed doi:10.1001/jamainternmed.2016.8254</jrn>

<bok>17 Mulley A, Trimble C, Elwyn G. Patients preferences matter: stop the silent misdiagnosis. The Kings Fund, 2012,

http://www.kingsfund.org.uk/publications/patients_preferences.html.</bok>

$<$ bok $>18 \quad$ Coulter A. Engaging patients in healthcare. Open University Press,

2011.</bok>

<eref>19 Coulter A, Roberts S, Dixon A. Delivering better services for people with long term conditions. Building the house of care. King's Fund. 2013.

www.kingsfund.org.uk/sites/files/kf/field/field_publication_file/delivering-better-servicesfor-people-with-long-termconditions.pdf.</eref $>$

$<$ jrn>20 Coulter A, Entwistle VA, Eccles A, Ryan S, Shepperd S, Perera R.

Personalised care planning for adults with chronic or long-term health conditions. Cochrane

Database Syst Rev 2015;(3):CD010523. doi:10.1002/14651858.CD010523.pub2.

PubMed $</$ jrn $>$

$<$ jrn>21 Maxwell RJ. Quality assessment in health. Br Med J (Clin Res Ed)

1984;288:1470-2. PubMed doi:10.1136/bmj.288.6428.1470</jrn> 
<bok>22 Institute of Medicine. Crossing the quality chasm: a new health system for the 21st Century. National Academy Press, 2001.</bok>

$<$ jrn $>23 \quad$ Blumenthal D, Abrams M, Nuzum R. The affordable care act at 5 years. $\mathrm{N}$ Engl J Med 2015;372:2451-8.. PubMed doi:10.1056/NEJMhpr1503614</jrn>

$<$ jrn $>24 \quad$ Song Z, Fisher ES. The ACO experiment in infancy-looking back and looking forward. JAMA 2016;316:705-6. PubMed doi:10.1001/jama.2016.9958</jrn>

$<$ jrn>25 Colla CH, Fisher ES. Beyond PCMHs and accountable care organizations: payment reform that encourages customized care. J Gen Intern Med 2014;29:1325-7..

PubMed doi:10.1007/s11606-014-2928-4</jrn>

<other>26 Draper R. The Obamacare operation. New York Times Magazine 2017

February 19.</other>

$<$ other>27 Gawande A. The hot spotters. The New Yorker 2011 January.</other>

$<$ bok>28 Trimble C, Wielawski I. The Atlanticare Special Care Center. Dartmouth

Center for Health Care Deliver Science, 2013.</bok>

$<$ bok>29 Trimble C. How physicians can fix health care: one innovation at a time.

American Association of Physician Leadership, 2015.</bok $>$

$<$ jrn $>30 \quad$ Condo J, Mugeni C, Naughton B, et al. Rwanda's evolving community health worker system: a qualitative assessment of client and provider perspectives. Hum Resour Health 2014;12:71.. PubMed doi:10.1186/1478-4491-12-71</jrn>

<eref $>31 \quad$ England NHS. Five year forward view. 24 October 2014.

https://www.england.nhs.uk/wp-content/uploads/2014/10/5yfv-web.pdf.</eref>

$<$ jrn>32 Fisher ES, Staiger DO, Bynum JPW, Gottlieb DJ. Creating accountable care organizations: the extended hospital medical staff. Health Aff (Millwood) 2007;26:w44-57. PubMed doi:10.1377/hlthaff.26.1.w44</jrn>

$<$ jrn>33 Meyer GS, Nelson EC, Pryor DB, et al. More quality measures versus measuring what matters: a call for balance and parsimony. BMJ Qual Saf 2012;21:964-8. PubMed doi:10.1136/bmjqs-2012-001081</jrn>

<jrn>34 Elwyn G, Barr PJ, Grande SW, Thompson R, Walsh T, Ozanne EM.

Developing CollaboRATE: a fast and frugal patient-reported measure of shared decision making in clinical encounters. Patient Educ Couns 2013;93:102-7. PubMed doi:10.1016/j.pec.2013.05.009</jrn>

<jrn>35 Elwyn G, Thompson R, John R, Grande SW. Developing IntegRATE: a fast and frugal patient-reported measure of integration in health care delivery. Int $\mathrm{J}$ Integr Care 2015;15:e008. PubMed doi:10.5334/ijic.1597</jrn>

$<$ jrn>36 Nelson EC, Eftimovska E, Lind C, Hager A, Wasson JH, Lindblad S. Patient reported outcome measures in practice. BMJ 2015;350:g7818. PubMed doi:10.1136/bmj.g7818</jrn>

$<$ jrn>37 Gittell JH, Seidner R, Wimbush A. A relational model of how highperformance work systems work. Organ Sci 2010;21:490-506 doi:10.1287/orsc. $1090.0446 .</ j r n>$

$<$ jrn>38 Sepucha KR, Fowler FJ Jr, Mulley AG Jr. Policy support for patient-centered care: the need for measurable improvements in decision quality. Health Aff (Millwood) 2004;Suppl Variation(Suppl Web Exclusive):VAR54-62. PubMed</jrn> $<$ jrn>39 Homer J, Milstein B, Hirsch GB, Fisher ES. Combined regional investments could substantially enhance health system performance and be financially affordable. Health Aff (Millwood) 2016;35:1435-43.. PubMed doi:10.1377/hlthaff.2015.1043</jrn> <eref>40 Colby S, Stone N, Carrtar P. Zeroing in on impact. Stanford Social Innovation Review 2004. https://ssir.org/articles/entry/zeroing_in_on_impact.</eref> 
<bok>41 Nelson EC, Batalden PB, Godfrey MM, Lazar JS. Value by design: developing clinical microsystems to achieve organizational excellence. Jossey-Bass, 2011.</bok>

$<$ jrn>42 Wolpert M, Vostanis P, Martin K, et al. High integrity child mental health: focusing on the person, not the problem. BMJ 2017;356:j1500.</jrn>

Table 1 Prevailing assumptions and how to tackle them

\begin{tabular}{|c|c|c|}
\hline Prevailing assumptions & Evidence to the contrary & $\begin{array}{c}\text { Sources of resistance to } \\
\text { change }\end{array}$ \\
\hline $\begin{array}{l}\text { Higher levels of healthcare produce } \\
\text { higher levels of health and wellbeing for } \\
\text { people and populations }\end{array}$ & $\begin{array}{l}\text { Healthcare contributes less to health } \\
\text { than social circumstances, including } \\
\text { education, and behaviour }\end{array}$ & $\begin{array}{l}\text { Biases toward: biomedical } v \text { social } \\
\text { science; specialism } v \text { general } \\
\text { knowledge; rescue } v \text { prevention }\end{array}$ \\
\hline $\begin{array}{l}\text { Clinical evidence alone tells us the right } \\
\text { thing to do for people in need of } \\
\text { healthcare }\end{array}$ & $\begin{array}{l}\text { Evidence is insufficient; patients' } \\
\text { preferences matter in decisions to } \\
\text { deliver services }\end{array}$ & $\begin{array}{l}\text { Bias toward the objective and } \\
\text { generalisable; neglect of context at the } \\
\text { level of the individual patient }\end{array}$ \\
\hline $\begin{array}{l}\text { Healthcare is the delivery of services by } \\
\text { professionals to people unable to } \\
\text { understand or do for themselves }\end{array}$ & $\begin{array}{l}\text { Much of healthcare is exchange of } \\
\text { information about achieving what is } \\
\text { possible and most valued }\end{array}$ & $\begin{array}{l}\text { Bias toward expertise, capabilities, and } \\
\text { agency of professionals with neglect of } \\
\text { that of people }\end{array}$ \\
\hline
\end{tabular}

Table 2 Design principles for high integrity health systems

$\begin{array}{ll}\text { Maxwell's quality } & \text { Institute of Medicine's } \\ \text { dimensions (1984) } & \text { aims (2001) }\end{array}$

Effectiveness for individuals:

Is the treatment given the best available in a technical sense, according to those best equipped to judge? What is their evidence? What is the overall result of the treatment?

\section{Efficiency and economy:}

Is the output maximised for a given input or is the input minimised for a given level of output? How does the unit cost compare with the unit cost elsewhere for the same treatment or service?

\section{Safe: \\ Are patients free from accidental injury due to error in the form of failure to complete a planned action as intended or the use of a wrong plan to achieve an aim? Effective: \\ Are services based on scientific knowledge provided to all who could benefit and not provided to those not likely to benefit? Is the best research evidence integrated with clinical expertise and patient values? Are results of care continuously monitored to improve care for all patients?}

\section{Efficient:}

Are resources used to get the best value for the money, by avoiding quality waste incurred by overuse and avoidable errors and reducing administrative and production costs?

\section{Design principles for high integrity health systems} (2017)

\section{Continuous learning from and}

with populations:

Are variations in process and outcome systematically monitored and reviewed? Is there a means of rewarding transparency and respect for local contexts? Is there systematic learning from variation in patients' goals and outcome preferences to improve decision quality? Is the expertise of patients, family, and carers reflected in learning collaborations? Are patients' outcome priorities used to determine effectiveness? Is there a means to identity what is not working for patients and to stop ineffective practice?

Co-production by teams of what is valued by individuals:

Are clinicians encouraged to work at the highest and best use of their knowledge and capabilities to coproduce valued outcomes with the people they serve? Are they supported to ensure patients understand the benefits, harms, and uncertainties of available interventions, and to find out what matters most to patients? Is overuse of costly healthcare avoided while basic health and social care needs are met? Are individuals' needs and wants measured and aggregated to 


\section{Access to services:}

Can people get this treatment or service when they need it? Are there any identifiable barriers to service-for example, distance, inability to pay, waiting lists, and waiting times - or straightforward breakdowns in supply?

\section{Equity:}

Is this patient or group of patients being fairly treated relative to others? Are there any identifiable failings in equity - for example, are some people being dealt with less favourably or less appropriately in their own eyes than others?

\section{Social acceptability:}

How humanely and considerately is this treatment or service delivered? What does the patient think of it? What would an observant third party think of it? What is the setting like? Are privacy and confidentiality safeguarded?

\section{Relevance to need:}

Is the overall pattern and balance of services the best that could be achieved, taking account of the needs and wants of the population as a whole?

inform purchasing and system investment decisions?

Timely:

Are waits and sometimes harmful delays reduced for both those who receive and those who give care?

\section{Equitable:}

Does care provided not vary in quality at the level of the population or individual because of characteristics such as gender, ethnicity, geographic location, and socioeconomic status?

\section{Patient centred:}

Is the care provided respectful of and responsive to the needs, values, and expressed preferences of the individual patient? Are services coordinated? Is information communicated, physical comfort attended to, and emotional support provided to patients, families, and friends?

\section{Access to information, support, and integrated services:}

Are service users given ready access to consistent information and support to assess their need for services and their role in managing them? Are those services integrated around patient needs and coordinated by the clinical delivery teams?

Supporting the personal agency of all people served:

Do care models support enhancement of motivation, confidence, and capabilities of all the people they serve - no exceptions - as well as those who serve? Do clinical teams include roles for people recruited for common lived experiences with, and empathy for, patients most at need? Are needs for health and social care recognised and met? Mutual accountability among all stakeholders:

Do care models tackle the interdependencies among people with health concerns, the professionals and staff who serve them, and the policy makers and leaders responsible for governance and stewardship of resources in the healthcare economy? Are appropriate metrics available for team members to hold themselves accountable in a compact based on shared goals and mutual respect? 